\title{
BET Inhibitor BMS-986158
}

National Cancer Institute

\section{Source}

National Cancer Institute. BET Inhibitor BMS-986158. NCI Thesaurus. Code C121849.

An inhibitor of the Bromodomain (BRD) and Extra-Terminal domain (BET) family of proteins, with potential antineoplastic activity. Upon administration, the BET inhibitor BMS-986158 binds to the acetyl-lysine binding site in the BRD of BET proteins, thereby preventing the interaction between BET proteins and acetylated histones. This disrupts chromatin remodeling and prevents the expression of certain growth-promoting genes, resulting in an inhibition of tumor cell growth. BET proteins (BRD2, BRD3, BRD4 and BRDT) are transcriptional regulators that bind to acetylated lysines on the tails of histones $\mathrm{H} 3$ and $\mathrm{H} 4$, and regulate chromatin structure and function; they play an important role in the modulation of gene expression during development and cellular growth. 